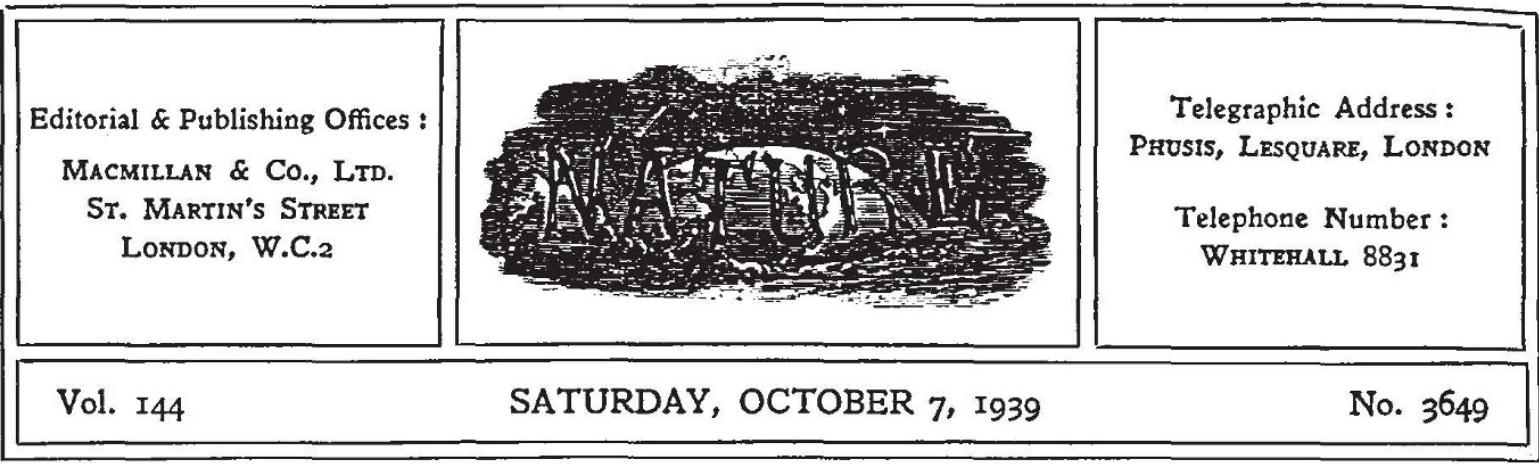

\title{
SEEKING AND SECURING THE PEACE
}

$\mathrm{T}$ HE fundamental war aims of France and Great Britain have been stated clearly by the Prime Minister as being "to redeem Europe from the perpetual and constantly recurring fear of German aggression, and to enable the people of Europe to preserve their independence and their liberties". Mr. Chamberlain's clear-cut phrasing expresses without ambiguity the spirit of determination with which the peoples of France and Great Britain have entered on the task which lies before them. It reflects with crystal clearness their resolve to restore to Europe conditions in which all its nations, without discrimination, may live side by side in the firm assurance that each will be free to develop to the full and at will in accordance with its traditions and culture under a settled order, of which the sanctity is recognized and respected as inviolable equally by all.

For the man of science and the student of the modes of development of human societies throughout the ages, this resolve of the people and their leaders is pregnant with hope for the future. In its grasp of realities it argues an appreciation of the rights and dignity of the individual, as well as of the integrity of national units, which while observing every consideration for the expression of that individuality, will not hesitate to demand that in its exercise each will contribute its appropriate share to the common stock-a contribution which will not only recognize the rights of other communities, but will also co-operate to relieve their necessities. For we may rest assured from our experience of the last war that, at the close of hostilities, innumerable social and economic problems will arise to demand with insistence the co-operation of each and everyone for their solution, under penalty for failure of the collapse of civilization. It is not in this war that there lurks the supreme danger for mankind-no war undertaken in the spirit of a crusade can fail to ennoble, though the individual perish-but in the peace which will follow. The elimination of an aggressor will not solve automatically the difficulties which in recent years have troubled the world and left it at odds with itself. The ending of this striving for dominance will do no more than prepare the way to the search for a remedy for these difficulties. It will make possible co-operative study in the light of an objective and scientifically detached view of the facts and the circumstances from which they have arisen.

In this way alone, and only in such conditions in international relations as it is our aim to establish, will it be possible to exercise a scientific control of future social and economic development, instead of the erratic play of economic forces damned by ill-judged and ill-conceived measures to bolster up a false and misguided conception of national prosperity, or even of national security. Though projected to stem the breakdown of the economic system, many such measures have only accentuated its weaknesses by wrecking the system of exchange and hampering distribution, so that valuable products of soil and sea have been destroyed as a glut, and whole populations have been on the verge of starvation when the earth brought forth in plenty. The Government of the United States, the richest country in the world in gold, the conventional medium of exchange which it could not use, has spent billions of dollars in an ineffective endeavour to save the sturdiest and most thrifty of its population from complete destitution and extinction. It is problems such as these in an intensity increased, it may be, 
a hundredfold, and probably with many more, which will still await solution 'after the war'.

Those of us who are old enough to remember clearly the outbreak of the two major wars in which the British people have been engaged in the present century-the Boer War and the War of 1914-18-will contrast, not without some amaze. ment, the difference in the expression of popular feeling with which we have entered upon this wara difference far more impressive in its undemonstrative exhibition of a complete unity of direction in purpose than the ebullient enthusiasm of the cheering crowds of the early August of 1914. Nor has there been any attempt to revive such an outbreak of popular feeling through the incitement of a vague and general statement of aims, an ideal for which we are to fight. We are not even assured, as politicians assured us in 1914, that this is "a war to end war". If we are the poorer in slogans, we are the more direct in purpose.

Yet, as the correspondence now appearing in the daily Press can show, there are those who hold that this direction of purpose might gain in strength and intensity if our ultimate aims were clearly defined. Mr. H. G. Wells, for example, in his letter in The Times of September 26, while arguing that "more and more of us are beginning to realize that there can be no more peace or safety on earth without a profound reconstruction of the methods of human living", goes on to assume that the Western world is quite inevitably marching towards a world collectivism. He suggests that we should make a genuine attempt to realize "that phase of world-wide plenty and safety" through a federation of mankind by free and unfettered discussion, simple and sincere, of the various means for the attainment of that end.

In Mr. Wells's view, the failure of the League of Nations to become such a federation of mankind as he envisages, was due to the fact that it was "too conservative of existing things, halfhearted, diplomatic". Is not the truth exactly contrary? Its most effective work has been in scientific research, the discussion of scientific, social, and economic problems, and the application of the results to practical problems-witness the virtual extirpation of the drug traffic in some of its darkest areas, and the measures for the sup. pression of the traffic in women. Here the League was at its most conservative. Such problems as these, and international co.operation in matters affecting literature, art and science, had for long been the order of the day. The League extended the scope of this co-operation, regularized and systematized it, and provided the machinery and organization for its more effective operation. Here it functioned with a most gratifying and surprising success. On the other hand, it was where it was most novel in its methods that it failed. For in a world of unharmonized peoples, many of whom were passing, or had passed recently, through a reconstruction on the principle of national or racial self-determination, it asked in some measure for an abrogation of a sovereignty either lately won or saved from destruction at enormous cost.

While the student of the forms of civilized society may see that the process of growth in the formation of human communities has been one of constant reintegration in larger and larger social unities-from family or kin to tribe, from tribe to people, from people to nation, and from nation to empire-it may well be that, in the long run, the logical goal of this ordered evolutionary process is the largest integration of all, the federation of mankind. But the time for this is not yet. Not merely is too large a proportion of the world's populations still in a state of retarded development-the populations of India and China alone, of whom a preponderating number is an impoverished peasantry, account for between a third and a half of the world's numbers-but the idea of nationality is too deep-seated as an emotional spring of action to be eliminated by the logical completeness of a theory. Though the excessive and frequently pernicious growth of nationalist sentiment in recent years has proved a setback to social and economic development, nevertheless a strong national tradition may be made a great asset to advancement, as the history of the world has shown.

In the discussion of problems of world-wide import-and all problems of a serious character nowadays tend to be world-wide in their application-in this discussion then, which is inevitable, racial and national traditions and cultures will each contribute a different point of vicw and a different outlook, whereby discussion will be the more capable of producing ultimate harmony, rather than any attempt to form an organization in which that tradition is likely to suffer a sense of frustration all too soon. For whatever may be the form or the machinery, be it league or federation, through which the peoples of the world will seek the co-operation which is inevitable unless 
the order of civilization is to crumble away, it is not discussion of general principles or machinery, in other words of the form of government and the means to secure it, which will save mankind from disaster, but the scientific study on a co-operative basis of the concrete problems which are vital to the well-being and the very existence of the unit from which the social aggregation is built up, whatever its form-the individual man, woman and child.

\section{THE NATIONAL REGISTER}

A NATIONAL REGISTER is, in essence, a continuous census. It is best regarded as a means of obtaining and recording that accurate knowledge of its human resources which the advance of science has made necessary to a civilized community. For more than a century past a periodic census has given us a record, at approximately ten-year intervals, of the numbers and distribution of the population in Great Britain, together with varying amounts of information about its composition as to sex, age, occupations, and so on. These records have become fuller during that time; and there has been pressure to make them also more frequent. A quinquennial census has been authorized, though not carried out. Now, under the stress of war, we have begun the transition from a periodic to a continuous record. Of course, it is not possible to publish continuously; but it should be possible to issue quarterly returns, akin to those now submitted by the registrars-general in respect to births, deaths, and marriages.

The information collected for this first edition of a British National Register is similar to, though less extensive than, that for recent censuses. It is limited to the name, sex, age, condition as to marriage, and occupation of every individual, with an additional column for members of the defence services. The plans for it were made during peace but are being carried out in a country at war, which is probably the reason for the extreme reduction of the form to be filled in by each householder. The most striking omissions are the absence of questions as to nationality, birthplace, workplace, or usual residence for those away from home. The first of these may perhaps be adequately replaced by the register of aliens kept by the police; the others are less urgent at present. But all these, and more, will be needed for a permanent national register.

The new feature which distinguishes this registration from all previous censuses is the provision for keeping it up to date. This takes the form of a legal obligation placed on all persons to notify every change of residence to the National Registration Officer of the district into which they move. Soon this must be extended to notification of all changes that affect the Register, and are not otherwise recorded, such as a change of occupation. The records of all these changes will make it possible to obtain information of increase or decrease of population in every local government district at frequent intervals. Everyone concerned with the administration of local government, or of education, has often felt the need for such information, which will now become available in respect of all the people. It has hitherto been available only in respect of certain groups, such as those on the live registers of the employment exchanges. It is urgently needed by all authorities responsible for public health. For all such services, and for local transport and retail distribution, a National Register will make possible greater efficiency, providing that it is well maintained.

The last full census was taken in 1931. It is, therefore, out of date for many purposes. The need for a prompt stocktaking of all our manpower is now urgent; and the experience of the War of 1914-18 shows that some such register can be invaluable in respect to both military and industrial organization for war and to the maintenance of the national life. By its regimentation and conscription of men and women, the German Reich has already got some corresponding record of its human resources. Not enough is known here about the system used to allow useful com. parisons with this British register.

It is unfortunate that the Register was not compiled months ago, before the outbreak of war made the task at once more urgent and more difficult. The evacuation of children and women from large towns, and the parallel removal of many other people will make the early months of the war a time of special difficulty in keeping in touch with the abnormal number of changes of residence. On the other hand, the fact that the Register is to 